\title{
O Materialismo Histórico Dialético
}

\author{
Dialetic Historical Materialism
}

\author{
Luís Henrique Zago \\ (Universidade Estadual Paulista, Brasil) \\ Allan Alberto Ferreira \\ (Universidade Estadual Paulista, Brasil) \\ Neiva Solange da Silva \\ (Universidade Estadual Paulista, Brasil) \\ Rodrigo Lima Nunes \\ (Universidade Estadual Paulista, Brasil)
}

\section{Resumo}

O presente trabalho aborda o método materialista histórico dialético, que é base para o desenvolvimento da teoria histórico-cultural. O objetivo é refletir sobre o método para ter clareza dos caminhos que percorreremos ao pesquisar. Para tanto, realizamos uma revisão de literatura para construir os entrelaçamentos necessários quanto a compreensão deste método. Consideramos que mesmo que não seja determinante, o método influenciará nas escolhas dos procedimentos de pesquisa. O elemento constituinte por excelência é a história, entendida não como simples sucessão de fatos em uma relação de causa e efeito, mas como a própria vida em movimento. Assim, postulamos que as pessoas não possuem história, elas são a própria história vivida em relação com os outros. O texto apresenta o materialismo histórico dialético como caminho para se alcançar conhecimentos que estejam para além do aparente.

Palavras-chave: Materialismo Históricodialético. Teoria Histórico-cultural. Lógica Formal. Lógica Dialética.

\begin{abstract}
The present work addresses the dialectical historical materialist method, which is the basis for the development of cultural historical theory. The goal is to reflect on the method to be clear about the paths we will take when researching. For this, we conducted a literature review to build the necessary interlacing as to the understanding of this method. We consider that even if it is not determinative, the method will influence the choices of research procedures. The constituent element par excellence is history, understood not as a simple succession of facts in a cause and effect relationship, but as life itself in movement. Thus, we postulate that people have no history, they are the history lived in relation to others. The text presents dialectical historical materialism as a way to achieve knowledge that is beyond the apparent.
\end{abstract}

Keywords: Dialectical Historical Materialism. Historical Cultural Theory. Formal Logic. Dialectical Logic. 


\section{Introdução}

Este texto resulta de análise e reflexões acerca do materialismo histórico dialético. Ele é parte dos nossos estudos para a composição de dissertação de mestrado que concluímos no ano de 2016. Neste, realizamos um trabalho teórico baseado em revisão de literatura, na qual buscamos embasamento em artigos e livros impressos de autores como Marx e Engels, Pinto, etc. O critério para a escolha destes autores está atrelado à proximidade de suas obras com o tema em questão, ou seja, estes autores abordam o materialismo histórico dialético.

A discussão emerge como preponderante para aqueles que pretendem utilizar a filosofia materialista histórico dialética como referência para suas ações e reflexões, seja em sala de aula, seja em estudos que estejam voltados a processos educativos.

Ao longo do texto citamos o materialismo e o idealismo e seus modos de organização lógica, para então focar nosso olhar em alguns aspectos importantes para a compreensão do materialismo histórico dialético.

Discutiremos que a filosofia materialista histórico dialética preconiza que a verdade não é alcançável imediatamente, apontaremos a necessidade de se elaborar uma constituição histórica dos fenômenos abordados, discutiremos a relação de causalidade nesta perspectiva filosófica, trataremos do fato de que o conhecimento está sempre em mudança e abordaremos o processo de abstração como condição para a produção de conhecimento.

Não pretendemos com esse trabalho esgotar os assuntos, apenas lançar luz sobre aspectos nos quais temos nos dedicado em nossa pesquisa. 


\section{Dois caminhos para o conhecimento}

Com base em Pinto (1979), tomamos como pressuposto a existência de duas grandes formas de compreensão da realidade, a saber: o materialismo e o idealismo. Estas duas formas mais do que modos de pesquisa são maneiras de posicionar-se ante o real. Cotidianamente, mesmo que não nos tornemos conscientes disso, estamos nos posicionando de modo idealista ou materialista.

Enquanto formas de abordagem do real, o materialismo e o idealismo podem ser organizados de diferentes modos lógicos. Basicamente, encontramos duas grandes formas de organização lógica: a formal e a dialética. Assim, ao trilharmos um caminho na busca de produzir conhecimentos podemos assumir como rota o idealismo combinado a lógica dialética ou formal ou então o materialismo combinado a lógica formal ou dialética. Julgamos que reflexões sobre este tema são de suma importância para a pesquisa. É possível chegar sem conhecer o caminho, mas muito mais difícil e arriscado. Ademais, entendemos não ser possível "servir a dois senhores" ou caminhamos na direção estabelecida por um método ou nos distanciamos dele no rumo do outro. Não é possível olhar para o real de modo idealista e concomitantemente ser materialista.

Pinto (1979) afirma que a dialética pode ser entendida em dois sentidos. Como lei da natureza, ou seja, como forma de organização e funcionamento intrínseco a natureza e como reflexão dos homens e mulheres sobre o real. Ao debruçar-se sobre a realidade para estudá-la as pessoas subjetivam a objetividade por meio da abstração, ao fazer isso elas podem traduzir a realidade dialética em pensamentos.

70 • Ágora Filosófica, Recife, v. 21, n. 2, p. 68-87, mai./ago., 2021 
A representação do real na forma de pensamento que é construída com base na dialética visa alcançar uma compreensão que avance para além do imediato.

\section{Imediato}

Tanto Marx (1985) quanto Hegel (2007) percebem que a realidade não se mostra em sua completude imediatamente, tornando necessárias formas peculiares de conhecimento como a ciência e a filosofia. Em contato apenas com o aparente não conseguimos aprender 0 essencial. Ao discutir a relação entre o salário e força de trabalho Marx (1985, p. 625) explicita isso:

À forma aparente, 'valor e preço do trabalho' ou 'salário', em contraste com a relação essencial que ela dissimula, o valor e o preço da força de trabalho, podemos aplicar o que é válido para todas as formas aparentes e seu fundo oculto. As primeiras aparecem direta e espontaneamente como formas correntes de pensamento; o segundo só é descoberto pela ciência (os grifos são nossos).

Assim, temos que as relações essenciais estão sempre para além de um primeiro olhar e são alcançadas apenas pelo uso da ciência. Para o autor este seria um dos objetivos da ciência, encontrar a verdade oculta nos fenômenos, desvelar o real para descobrir o essencial que forma e define o aparente. Hegel (2007, p.41) ao esclarecer os objetivos da Fenomenologia do Espírito caminha no mesmo sentido de Marx:

O que esta Fenomenologia do Espírito apresenta é o vir-a-ser da ciência em geral ou do saber. O saber, como é inicialmente - ou o espírito imediato - é algo carente-de-espírito: a consciência sensível. Para tornar-se saber 
autêntico, ou produzir o elemento da ciência que é seu conceito puro, o saber tem de se esfalfar através de um longo caminho.

A consciência sensível não é capaz de produzir um saber autêntico que possa ser considerado efetivamente conceitual. Os conceitos obtidos com base apenas no que os sentidos conseguem captar são na verdade pseudoconceitos, não obtendo o nível de generalização necessários a uma orientação segura no real.

É famosa a contenda de Hegel com os irracionalistas, que consideravam a intuição um instrumento privilegiado do conhecimento humano; para eles, o que era notado intuitivamente já possuía valor de verdade, não existindo a necessidade de se "esfalfar através de um longo caminho" como indicado por Hegel e Marx. A impressão genérica e muitas vezes caótica obtida no ponto de partida seria suficiente. Da seguinte forma Hegel (2007, p.24) expõe a concepção irracionalista:

Com efeito, se o verdadeiro só existe no que (ou melhor, como o que) se chama quer intuição, quer saber imediato do absoluto, religião, ser - não o ser no centro do amor divino, mas o ser mesmo desse centro -, então o que se exige para a exposição da filosofia é, antes, o contrário da forma do conceito. O absoluto não deve ser conceptualizado, mas somente sentido e intuído; não é o seu conceito, mas seu sentimento e intuição que devem falar em seu nome e ter expressão.

Propugnar que a imediatez livre de mediações possa ser mais verdadeira que uma percepção acurada do real significa considerar que apenas uma parte das coisas 
é a verdade. É evidente que o aparente é também o real, mas é apenas uma parcela deste e invariavelmente a menor. As coisas são compostas por uma infinidade de relações muitas das quais distantes do fenômeno. A superfície do lago também é o lago, mas a menor parte deste e o que nela aparece é condicionado por uma infinidade de coisas fora do lago, como o céu que ele reflete e por outras na profundidade de suas águas e que não conseguimos alcançar se ficamos apenas na superficialidade. Assim, o real para ser efetivamente compreendido demanda um olhar que vá para além da superficialidade aparente. Hegel e Marx julgam a posição dos irracionalistas ingênua. Mesmo considerando que o fenômeno e a essência são uma unidade é evidente para estes filósofos que imediatamente os fenômenos não podem revelar o ser das coisas.

Para se conhecer efetivamente as coisas não basta se contentar com a imediaticidade, esta revela muito pouco a respeito dos objetos. Os fatos empíricos percebidos isoladamente e imediatamente são o ponto de partida, o começo de toda pesquisa, porém limitar-se a eles é impedir a possibilidade de alcance de um conhecimento melhor elaborado e mais preciso. Como afirma Hegel (2007, p.27):

Quando queremos ver um carvalho na robustez de seu tronco, na expansão de seus ramos, na massa de sua folhagem, não nos damos por satisfeitos se em seu lugar nos mostram uma bolota. Assim a ciência, que é a coroa de um mundo do espírito, não está completa no seu começo.

Assim, podemos afirmar que de modo imediato não conseguimos alcançar a essência das coisas. No caso dos 
seres humanos a essência está na interrelação do biológico com o social que se amalgamam na construção histórica e ininterrupta de uma personalidade singular e irrepetível. Não é possível compreendermos as pessoas sem considerar sua história constitutiva.

\section{A História e a Relação de Causalidade}

Imediatamente não conseguimos captar o elemento constitutivo dos objetos e pessoas, que é justamente sua história. A origem das coisas e das pessoas não está diante de nossos olhos, precisamos reconstitui-la como detetives a partir das pistas deixadas no presente. Considerar a história como elemento constitutivo significa afirmar que as pessoas e coisas não tem apenas história elas são a sua própria história, do contrário a história não seria o processo que constitui, mas apenas o que antecede. Isso seria um erro, pois neste caso, teríamos que afirmar que o que antecede não tem relação de determinação com o que sucede, o que evidentemente não tem sentido.

Considerar que as pessoas e coisas são a própria história é admitir que o desenvolvimento se "autocondiciona" ou "auto-determina". O desenvolvimento é um processo histórico, e não pode o processo histórico ser determinado por algo que não seja seu próprio movimento. Evidentemente temos de considerar que nessa determinação não são apenas nossas ações individuais que contam, mas a integração e a união de diferentes unidades em um todo, em um conjunto de relações que são síntese de muitas determinações constituídas historicamente e que estão em um movimento em que se contradizem constantemente. A síntese não é o acabamento, ela, que está sempre se

74 • Ágora Filosófica, Recife, v. 21, n. 2, p. 68-87, mai./ago., 2021 
refazendo no decorrer da própria história, é a própria totalidade concentrada, não de elementos isolados, somados, mas a totalidade integrada de unidades dinâmicas que não podem existir umas sem as outras.

Geralmente tendemos a julgar a realidade de modo cartesiano, afirmando que as coisas estão em simples relações de causa e efeito. Isto nos leva a separá-las e a pensar que se somos assim, é porque seríamos o efeito final de uma relação de mão única, em que o já constituído determina o que está no gerúndio, o que seria uma simplificação limitadora da realidade. Não estamos negando que as coisas tenham uma causa, o que existe tem de surgir de algo que é, afinal o nada não pode vir a ser, o que já era propalado por Parmênides (1996, p.21) em suas duas vias da verdade a mais de dois milênios. $O$ problema está em considerar que a determinação se dá em uma relação em que um objeto põe o outro sem ser por ele afetado. Sobre isso escreve Hegel (2007, p. 26):

O botão desaparece no desabrochar da flor, e poderia dizer-se que a flor o refuta; do mesmo modo que o fruto faz a flor parecer um falso ser-aí da planta, pondo-se como sua verdade em lugar da flor: essas formas não só se distinguem, mas também se repelem como incompatíveis entre si. Porém, ao mesmo tempo, sua natureza fluida faz delas momentos da unidade orgânica, na qual, longe de se contradizerem, todos são igualmente necessários. E essa igual necessidade que constitui unicamente a vida do todo. Mas a contradição de um sistema filosófico não costuma conceber-se desse modo; além disso, a consciência que apreende essa contradição não sabe geralmente libertá-la - ou mantê-la livre - de sua unilateralidade; nem sabe reconhecer no

Ágora Filosófica, Recife, v. 21, n. 2, p. 68-87, mai./ago., 2021 • 75 
que aparece sob a forma de luta e contradição contra si mesmo, momentos mutuamente necessários.

Botão, flor e fruto ainda que distintos como unidades, são componentes de um mesmo processo de desenvolvimento. Mesmo que o emergir de um represente o ocaso do outro isso não significa que eles se anulam, mas que se superam por incorporação. A flor carrega em si as marcas da vivência do botão, bem como o fruto as da flor. Em sua diversidade eles se completam e realizam o desenvolvimento histórico da planta. O jovem traz em si toda a vivência, ressignificada pelo presente, do seu passado como criança, esta o marca de modo indelével e mesmo que superada faz com que ele seja quem é.

O novo possui como causa realidades já existentes que temporalmente são anteriores e constitutivas dele. $\mathrm{O}$ fato de alguns elementos serem causa de outros não os isola na relação com o que é instituído. O novo, em necessária relação com o velho, pode contribuir para manter, alterar ou mesmo elidir o que o causou. Nesta acepção o novo pode inclusive ser a causa do que existia anteriormente a ele. Em virtude disto torna-se praticamente impossível estabelecer uma compreensão baseada na causa e efeito linear e com um único sentido.

Neste sentido é a relação recíproca a causa ontológica por excelência. Assim, determinar quem é a causa, quem o efeito depende da abrangência da análise realizada. Devemos considerar também, que o que produz efeitos agora foi ou ainda é causado por alguma coisa.

São comuns trabalhos de psicologia tratar o

76 • Ágora Filosófica, Recife, v. 21, n. 2, p. 68-87, mai./ago., 2021 
indivíduo como uma "monada", afirmando que os homens e mulheres nas suas relações com ele são apenas objetos de seu pensamento ou de sua ação. Basta a observação empírica simples para desbancar esta afirmação. Quase nunca a ação humana tem por sujeito um indivíduo isolado. Como afirma Goldman (1967, p.18) "O sujeito da ação é um grupo, um 'Nós', mesmo se a estrutura atual da sociedade, pelo fenômeno da reificação, tende a encobrir este 'Nós' e a transformá-lo numa soma de várias individualidades distintas e fechadas umas às outras".

As relações de causalidade se constituem em um processo histórico. O que faz com que a compreensão da realidade pressuponha uma investigação de como se processam ao longo da história as mudanças qualitativas. Como já afirmamos, a realidade, como síntese de múltiplas determinações, não se revela instantaneamente, com mera intuição, sua compreensão exige um estudo genético-causal que deslinde a origem e anteveja as metas almejadas no caminhar. Segundo Delari Jr. (2014):

A síntese só será produzida mediante processo de desenvolvimento que se perfaz sempre no tempo, breve ou longo. Por isso a análise é "genético-causal". Cujos principais requisitos são: (a) tomar o objeto de análise como "processo" e não "objeto" (no sentido de "coisa"); (b) buscar sua essência e não deter-se apenas em sua aparência; (c) explicálo por suas causas genéticas e não apenas descrever seus efeitos.

A compreensão da realidade implica um estudo que avance para além do aparente e abarque a processualidade da vida. As coisas e pessoas possuem sempre uma história constitutiva de suas aparências e 
significados estes só são obtidos em um estudo que considere a realidade como mutável.

\section{Conhecimento e a Mudança}

Consideramos que mesmo com um estudo genético-causal não conseguiremos abarcar todo o real, não há forma material alguma possível de reproduzir o real, mas sim de compreender as principais leis que o constituem o que não é o mesmo que reproduzir o próprio real. A reflexão atinente ao real pode ser fiel ou falsa, ampliar o conhecimento sobre ou não, mas nunca ser a reprodução plena da realidade. Em síntese todo pensamento será uma dialética entre a constituição de uma compreensão fiel do real, e alguma incompreensão inevitável sobre como é de fato, na totalidade inapreensível de suas determinações, a realidade.

A forma de conhecimento mais bem elaborada a respeito das coisas só se dá e tem sentido na medida em que amplia nossa capacidade de modificar o curso da realidade. Apenas por meio do pensamento não temos a oportunidade de testar a realidade para averiguar nossos conhecimentos. Ademais, no contato prático com as coisas descobrimos que elas não poderiam ser alcançadas apenas com a força do pensar. A resistência dos corpos, sua consistência, nossa força em relação a eles entre outras coisas demandam a ação prática. Apenas na prática conseguimos compreender as leis que regem o real.

Um estudo que busque conhecer profundamente algo e não permita agir na direção da mudança de seu curso, provavelmente não alcançará à essência. Devemos entender que não só se muda aquilo de que se soube a essência, mas se chega a saber a essência tão somente agindo sobre as coisas para saber até onde é possível 
mudá-las ou não. É o processo de mudança que torna possível o conhecimento da essência.

É claro que a realidade se modifica mesmo que não tenhamos conhecimento dos mecanismos de seu funcionamento, porém um agir consciente deve conhecer as leis que determinam o real. Se as leis que regem o real são desconhecidas dificilmente conseguiremos fazer com que sigam tal ou qual curso em função de nossos planos. Neste sentido incorporar as leis do real pode ser a condição para transformar o real em um novo curso.

\section{Processo de Abstração}

A tentativa de compreender o real ao ponto de alcançar sua essência impõe a necessidade de refletir sobre a relação entre o concreto e o abstrato. No materialismo histórico dialético o concreto não é entendido apenas como o empírico (DELARI JUNIOR, 2009), ou seja, a experiência pela experiência. O concreto é percebido como a síntese de múltiplas determinações. Como afirma Marx "O concreto é concreto por que é síntese de múltiplas determinações, portanto, unidade da diversidade" (MARX, 2011, p.54). O que exige daquele que quer entendê-lo olhar que se direcione para além do que se apresenta diretamente aos sentidos. $O$ método dialético irá justamente buscar as relações por trás dos fenômenos. Sobre esta posição marxiana escreveu Walhens (apud KOSIK, 1976, p.17) "O marxismo é o esforço para ler, por trás da pseudo-imediaticidade do mundo econômico reificado as relações inter-humanas que o edificaram e se dissimularam por trás de sua obra".

Nesse sentido entende-se a proposição de Marx (2011) de que é preciso "ascender ao concreto". Ele é uma meta elevada, não só ponto de partida eventual. Mas para

Ágora Filosófica, Recife, v. 21, n. 2, p. 68-87, mai./ago., $2021 \cdot 79$ 
alcançarmos o concreto, a abstração não pode bastar-se, nem perder seu vínculo com a vida social, com as necessidades e lutas de cada sociedade.

A abstração implica a análise das unidades a serem estudadas. Segundo Marx (1985) apenas por meio de um processo de análise correta das unidades da realidade é possível compreender o real de forma científica. Sobre a necessidade de análise promovida pela abstração afirma o filósofo no prefácio da primeira edição de "O capital": “Na análise das formas econômicas, não se pode utilizar nem o microscópio nem reagentes químicos. A capacidade de abstração substitui estes meios" (MARX, 1985, p.4).

Cumpre destacar que a análise a qual nos referimos difere profundamente da proposta por Descartes (1996) em seu método de abordagem correta do real, no "Discurso do método". A proposta cartesiana de análise além de desconsiderar os aspectos históricos e sociais da realidade, não passa de um fracionamento para a descrição do imediatamente visível nas inúmeras partes.

As inúmeras partes são fracionadas e posteriormente alinhavadas sem se considerar que juntas elas são mais que a sua simples soma. Ao se articularem formando uma totalidade, as partes individuais passam a deter características que não possuiriam se permanecessem separadas. Isso aumenta o trabalho da análise materialista, pois não adianta nada dizer quais são as múltiplas determinações que constituem o objeto concreto e que generalizadas constituem o concreto pensado, é preciso estabelecer as relações de cada determinação com as demais, o que no plano do pensamento envolve a formação de um "sistema de conceitos". Um conceito científico não é ligado diretamente ao objeto real, mas é mediado por outro 
conceito, formando "redes", ou melhor, "sistemas conceituais" - o que envolve hierarquização de graus de generalidade, trânsito por diferentes conteúdos concretos, além de todo o conteúdo sensível do conceito, que não é tomado como uma simples estrutura de signos abstrata sem sensibilidade, sem afetos, sem imaginação, etc.

Feita a análise, é preciso reconstruir o objeto, que é o momento que se ascende à "síntese" de múltiplas determinações, faz-se o caminho inverso do mais simples ao conceito que foi o ponto de partida, que ao ser atingido não será mais representado como um todo caótico, mas como uma rica totalidade de determinações. Por meio desse processo o concreto é pensado não em sua completude, mas ao menos de modo organizado.

Mesmo depois de superada a representação caótica do todo e alcançada a totalidade como determinação de relações diversas, esta não é o real, mas apenas o que o ser humano com suas limitadas capacidades consegue apreender e formular sobre o real. A realidade é infinitamente mais complexa do que a capacidade humana de descrever e pensar. Ademais, o real está em constante fluir o que exige um esforço de apreensão que considere as coisas em processo de transformação.

\section{Idas e Vindas}

A afirmação de que a produção do conhecimento deve considerar o processo constante de transformação da realidade não é dominante na história do pensamento ocidental. Durante a maior parte desta predominaram tentativas de encontrar fórmulas imutáveis ou caminhos inalteráveis como proposições que sejam à verdade sobre o real. Seja no pensamento teológico/religioso em que todos os caminhos fazem parte de um plano pré-definido

Ágora Filosófica, Recife, v. 21, n. 2, p. 68-87, mai./ago., $2021 \cdot 81$ 
por uma divindade onisciente, seja, na tradição filosófica platônico/aristotélica a consideração da transformação é vista como secundária. A verdade estaria na formulação de um conceito ou processo inalterável.

Na modernidade o entendimento de que tudo está em constante construção e reformulação invalidou a posição dos racionalistas e empiristas. Ainda que fundamentados em experimentos e não apenas em abstrações teóricas estas duas formulações filosóficas, que sustentaram a prática científica nascente, acabam por reproduzir a essência das posições platônica e aristotélica.

Havia a crença em um constante progresso que alcançaria a verdade clara e evidente, mesmo que o ponto de partida fosse a dúvida. Segundo Goldman (1967) o racionalismo partindo de ideias inatas ou claras e evidentes e o empirismo partindo da sensação ou percepção elaboraram um conjunto de postulados sob os quais edificaram uma base, que acreditavam, promoveria um avanço em linha reta com a certeza de que uma questão superada não deve mais ser retomada.

A dialética não considera avançar em uma linha reta de constante progresso, na direção de verdades absolutas. Segundo Goldman $(1967$, p.6) “... o pensamento nunca avança em linha reta, pois toda verdade parcial só assume sua verdadeira significação por seu lugar no conjunto, da mesma forma que o conjunto só pode ser conhecido pelo progresso no conhecimento das verdades parciais". Cada avanço que obtemos amplia nossa capacidade de enxergar a realidade, possibilitando perceber coisas que antes não víamos o que pode trazer à tona problemas antigos em novas perspectivas ou suscitar novos problemas para os quais ainda são necessários o desenvolvimento de recursos. 
O ser humano agindo sobre outros seres não humanos, sobre seus semelhantes e sobre si próprio é capaz de reconhecer a realidade como problemática, por que nestas ações desenvolve recursos culturais simbólicos para isso, assim à medida que vamos descobrindo novas coisas e ampliando nossa percepção atinente ao real, vamos concomitantemente constatando que nosso conhecimento é ainda imperfeito e limitado. Esta constatação motiva o desenvolvimento de novas redes de conceitos e o desenvolvimento de recursos que possibilitem perscrutar de forma mais percuciente a realidade.

O pesquisador lança mão das palavras para dar conta de abordar o real que não se esgota nas próprias palavras, mas que sem elas não passa para o plano consciente do cientista e da sociedade. Não há conceito científico que possa reproduzir plenamente o real. Porém justamente porque o conceito científico consegue afirmar alguma coisa é que se percebe que existe mais a ser dito. Neste sentido todo discurso científico é cheio de lacunas e silêncios. Temos de considerar que "O pensamento é apenas um aspecto parcial de uma realidade menos abstrata: o homem vivo e inteiro" (GOLDMAN, 1967, p.8).

Os seres humanos singulares são apenas ínfimas partes do que a totalidade das relações sociais representa. Goldman (1967, p.12) considerando que as pessoas e sua produção só podem ser compreendidas se pensadas como parte de um contexto que as envolve e que por elas é criado afirma que o estudo de um texto implica não isolar o autor de seu contexto. Segundo o autor:

$\mathrm{Em}$ todos estes casos estamos diante do mesmo procedimento: são isolados de seu contexto certos elementos parciais de uma

Ágora Filosófica, Recife, v. 21, n. 2, p. 68-87, mai./ago., $2021 \cdot 83$ 
obra, deles são feitas totalidades autônomas

e constata-se em seguida a existência de elementos análogos em uma outra obra, com a qual se estabelece, então, uma aproximação. Cria-se assim uma analogia artificial, deixando de lado, conscientemente ou não, o contexto, que é inteiramente outro, e que dá mesmo a esses elementos semelhares significação diferente ou oposta (GOLDMAN, 1967, p.12).

As tentativas de seguir em uma linha reta partindo de verdades absolutas que calem os problemas tomam a forma de clichê, de cânone, de dogma, de superstição ou de preconceito, são posturas que buscam não problematizar, mas apenas divulgar posições para serem repetidas e obedecidas, o que obsta o avanço.

O materialismo dialético tem a vantagem de considerar as coisas em seu movimento constituidor. Neste sentido promove uma compressão do processo de formação da realidade. $O$ que possibilita um entendimento do passado, presente e dos possíveis caminhos para onde se direciona o real estudado.

\section{Considerações Finais}

Ao longo do texto apresentamos o materialismo histórico dialético como uma forma de conhecimento que enfatiza que a compreensão da realidade não é alcançável imediatamente, mas por meio da prática transformadora e de conceitos mediadores que possibilitem um olhar que vá para além do aparente. Apontamos que para se alcançar isto é imprescindível a elaboração da constituição histórica dos fenômenos estudados. O estudo da constituição histórica nos levou a discutir a relação de 
causalidade tal como entendida pelo materialismo histórico dialético.

A realidade está sempre em transformação, o que nos levou a afirmar que o conhecimento está em mudança, que só é compreensível por meio de um estudo que considere este movimento do real.

Se a meta da ciência for encontrar ideias que sejam a adequação perfeita à realidade, dificilmente ela será atingida. O pensamento não consegue reproduzir o real, afinal ele se organiza em códigos linguísticos e o real é carne, sangue, pedra, poeira etc. A ciência não pode ser "cama de Procusto" que exige a adequação perfeita, total e imutável, o que seria incompatível com o fluir da vida.

Afirmarmos a incapacidade do pensamento de reproduzir o real, não significa negar a produção de conhecimento. Mesmo um conhecimento limitado a respeito do real é melhor que nenhum. Ademais, temos de considerar que quanto maior for nosso conhecimento, melhor será a nossa capacidade de alterar a realidade para formas mais conscientes, éticas e livres.

O materialismo histórico dialético apresenta-se como método para o conhecimento da realidade. Entendemos que por suas proposições e indicações de caminhos a serem percorridos para a produção do conhecimento podemos alcançar uma visão mais percuciente atinente ao real, deslindando os elementos constitutivos da realidade, o que indubitavelmente é importante ao trabalho científico.

Destarte, a utilização do materialismo histórico dialético como recurso para a compreensão da realidade pode ampliar o conhecimento sobre a realidade e seus processos. 


\section{Referências}

DELARI JUNIOR, A. Projeto de psicologia na perspectiva de Vigotski para o século XXI. 19 p., 2014. Disponível em: https://www.facebook.com/circulodavilaoperaria. Acesso em: 12 de janeiro de 2014.

DELARI JUNIOR, A. Vigotski e a prática do psicólogo: em percurso da psicologia geral à aplicada. Mimeo. Umuarama, 2009. 40 p. (2 $2^{\text {a }}$ versão).

DESCARTES, R. Discurso do Método. São Paulo. Nova Cultural, 1996.

ESPINOSA, B. Ética. São Paulo: Atena, 1957.

GOLDMANN, Lucien. O todo e as partes. In: Dialética e cultura. Rio de Janeiro, Paz e Terra, 1967.

HEGEL, Georg W.F. Fenomenologia do Espírito. $4^{\mathrm{a}}$. Petrópolis: Vozes, 2007.

KOSIK, Karel. Dialética do Concreto. $2^{\mathrm{a}}$ ed. São Paulo: Paz e Terra, 1976.

MARX, Karl. O capital: Crítica da economia política. $10^{a}$ ed São Paulo: Difel, 1985.

MARX, Karl. Grundrisse: Manuscritos econômicos de 1857- 1858 Esboços da crítica da economia política. São Paulo: Boitempo, 2011.

MARX, Karl. Manuscritos econômicos-filosóficos. São Paulo: Boitempo, 2004.

PARMÊNIDES. In: Pensadores: pré-socráticos. São Paulo: Nova Cultural, 1996.

PINTO, A. V. Ciência e Existência: problemas filosóficos da pesquisa científica. Rio de Janeiro: Paz e Terra, 1979.

\section{Luís Henrique Zago}

Doutorando em Educação pela Universidade Estadual Paulista UNESP, Presidente Prudente, SP. Atualmente trabalha como psicólogo clinico, professor da Fundação educacional de 
Araçatuba (FEA), professor efetivo de filosofia da Rede Pública de ensino do Estado de São Paulo atuando no Programa de Ensino Integral (PEI).

E-mail: luishenriquezago@hotmail.com

\section{Allan Alberto Ferreira}

Mestrando em Educação pela Universidade Estadual Paulista UNESP, Marília, SP. Formado em psicologia pela Faculdade Educacional de Araçatuba, é pós-graduado em psicomotricidade, educação e aprendizagem pela Universidade do Oeste Paulista-UNOESTE.

E-mail: allandisel@hotmail.com

\section{Neiva Solange da Silva}

Mestre em Educação pela Universidade Estadual Paulista UNESP, Presidente Prudente, SP. Atua como Supervisora de Ensino na Secretaria Municipal de Educação do município de Araçatuba-SP.

E-mail: neiva_lee@hotmail.com

\section{Rodrigo Lima Nunes}

Doutor em Educação pelo programa de Pós-Graduação em Educação da Universidade Estadual Paulista Júlio de Mesquita Filho (UNESP), Faculdade de Ciências e Tecnologia (FCT), campus de Presidente Prudente-SP (2019). Mestre em Educação pelo mesmo programa (2013) (financiamento da FAPESP), com formação inicial em Educação Física (licenciatura) também pela Faculdade de Ciências e Tecnologia (UNESP-Presidente Prudente-SP) (2010).

Email: ronunes29@gmail.com.

Submetido: 01/09/2021

Aprovado: 15/09/2021 